CASE REPORT

\title{
Diffuse lung disease caused by cotton fibre inhalation but distinct from byssinosis
}

\author{
H Kobayashi, S Kanoh, K Motoyoshi, S Aida
}

Thorax 2004;59:1095-1097. doi: 10.1136/thx.2003.014027

A 66 year old man had inhaled cotton fibre for 50 years at his workplace. He did not have any respiratory symptoms. Chest CT scans revealed diffuse centrilobular and peribronchovascular interstitial thickening. Lung biopsy specimens confirmed the presence of string-like foreign bodies as well as granulomas and fibrosis in the peribronchial region. Infrared spectrophotometry confirmed that the foreign bodies were composed of natural cellulose. This is the first study to show directly by examination of biopsy samples that cotton fibre inhalation can cause diffuse lung disease. The clinical features of the disease were entirely different from those of byssinosis.

B yssinosis is a disease caused by the inhalation of cotton, flax, and hemp fibres while working. It is the general term for a syndrome and the clinical description is well established. ${ }^{12}$ This report describes a new type of diffuse lung disease caused by cotton inhalation which was confirmed pathologically and had marked differences from byssinosis.

\section{CASE REPORT}

A 66 year old man underwent chest radiography during a health check and diffuse infiltrative opacities were detected in the bases of both lungs. He had no respiratory symptoms, including cough, sputum, or dyspnoea. He was an ex-smoker (6 pack-years) who had stopped smoking about 30 years earlier. The patient had been involved in the manufacture and repair of futons for 50 years, working at a small futon shop since he was 16 years old. Although cotton fibres were often floating freely in the atmosphere of the workroom, no respiratory protection for the dust was provided. On examination he had fine inspiratory crackles in the bilateral lower lung fields.

Laboratory tests revealed the following: white blood cell

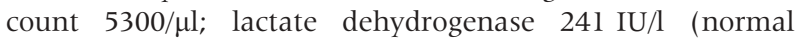
$\leqslant 220$ ); KL-6 $607 \mathrm{U} / \mathrm{ml}$ (normal $\leqslant 500$ ); surfactant protein A $57.7 \mathrm{ng} / \mathrm{ml}$ (normal $\leqslant 43.8$ ); surfactant protein D $224 \mathrm{ng}$ / $\mathrm{ml}$ (normal $\leqslant 110$ ); $\mathrm{C}$ reactive protein $0.6 \mathrm{mg} / \mathrm{dl}$ (normal $\leqslant 0.3$ ). Serological tests showed no evidence of collagen disease. Arterial blood gas analysis revealed a pH of 7.452, $\mathrm{PaCO}_{2}$ of $35.5 \mathrm{~mm} \mathrm{Hg}$, and $\mathrm{PaO}_{2}$ of $76.2 \mathrm{~mm} \mathrm{Hg}$. Lung function tests gave the following results: vital capacity $2.78 \mathrm{l}(87 \%$ of predicted), forced expiratory volume in 1 second/forced vital capacity $\left(\mathrm{FEV}_{\mathrm{l}} / \mathrm{FVC}\right) 75 \%$, peak expiratory flow $7.53 \mathrm{l} / \mathrm{min}$ (104\% of predicted), and carbon monoxide transfer factor (TLCO) $12.7 \mathrm{ml} / \mathrm{min} / \mathrm{mm} \mathrm{Hg}(86 \%$ of predicted). As indicators of small airway function, maximal mid expiratory flow was $1.42 \mathrm{l} / \mathrm{s}$ (49\% of predicted) and $25 \%$ forced expiratory flow was $0.49 \mathrm{l} / \mathrm{s} \quad(31 \%$ of predicted). Analysis of bronchoalveolar lavage fluid revealed a cell count of $2.2 \times 10^{5} / \mathrm{ml}$ with $15 \%$ lymphocytes (CD4/CD8 ratio of 4.65$)$ and $85 \%$ macrophages. A high resolution CT (HRCT) scan of the lungs showed subpleural ground glass opacities and an interface sign at the surface of the visceral pleura, while centrilobular and peribronchovascular interstitial thickening were identified as the inverted $\mathrm{Y}$ and $\mathrm{V}$ sign (fig l).

Transbronchial lung biopsy was performed but failed to provide a pathological diagnosis. A video-assisted thoracoscopic biopsy was therefore undertaken with the patient's informed consent and three biopsy specimens were obtained. All three specimens had similar histological features of tiny granulomas and fibrous thickening of the peribronchiolar interstitium (fig 2). Scattered eosinophilic string-like foreign bodies were detected within the areas of peribronchiolar fibrosis (fig 3A and B). These string-like foreign bodies were $20-30 \mu \mathrm{m}$ thick and were surrounded by histiocytes that formed granulomas with an overall size of 100-150 $\mu \mathrm{m}$. It was unclear whether or not the foreign bodies had a hollow oval structure on cross section (a characteristic feature of cotton fibres).

Two additional tests were conducted to identify the stringlike foreign bodies. The samples were heated to $300^{\circ} \mathrm{C}$ and, since this did not melt them, it was concluded that they were natural fibres. Spectral analysis of the foreign bodies with an

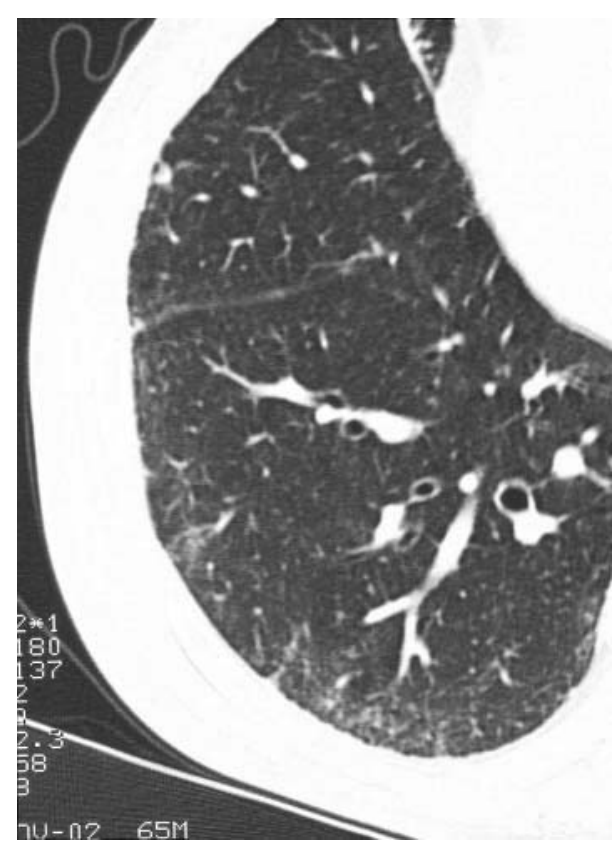

Figure 1 HRCT scan of the lung showing subpleural ground glass opacities, an interface sign at the surface of the visceral pleura, and centrilobular and peribronchovascular interstitial thickening. 


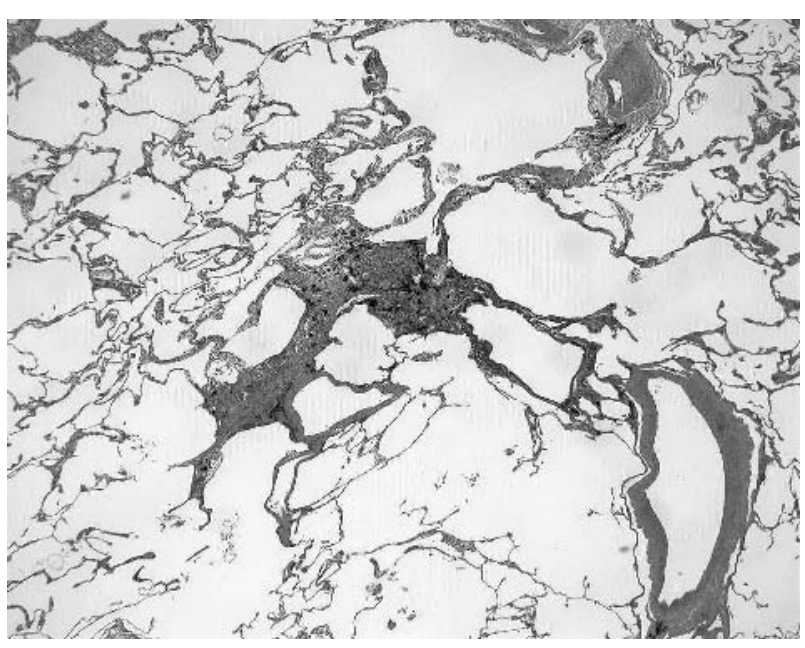

Figure 2 Low power histological view of video-assisted thoracoscopic biopsy specimen showing fibrous thickening of peribronchiolar interstitium. H\&E staining, magnification $\times 4$.

infrared spectrophotometer (IR $\mu$ s Molecular Microanalysis System, Spectra-Tech Inc, USA) showed that the foreign bodies had a similar spectral pattern to that of cellulose. Based on the results of these tests and the patient's occupational exposure to cotton inhalation, the cellulose fibres were concluded to be cotton.

Electron microscopy was also performed but we were unable to identify the foreign bodies because they were sparsely distributed in the biopsy specimens.

\section{DISCUSSION}

This patient had been engaged in the manufacture and repair of futons for 50 years, during which period he had been exposed to cotton dust without respiratory protection. The futon is a traditional Japanese style of bedding made of cotton packed inside a cloth bag, and is similar to the mattress used on a western bed. Byssinosis is a well known disease caused by the inhalation of cotton and is the general term applied to various acute and chronic conditions that afflict workers who process cotton, flax, and hemp fibres. ${ }^{12}$

However, the patient described here did not have any of the recognised symptoms of byssinosis (cough, wheeze, or Monday morning fever) and lung function tests did not show the relevant abnormalities (no reduction in $\mathrm{FEV}_{1}$ but small airway disturbance). He did not have any of the histopathological features characteristic of byssinosis such as mucus gland hyperplasia and infiltration of neutrophils into the bronchi. ${ }^{3}$ There was also no eosinophilic infiltration (reflecting allergy) in the biopsy specimens. Since cellulose fibres were found in the lungs of our patient and a foreign body tissue reaction to cellulose was confirmed, it was concluded that he suffered from a condition that could be called cotton dust pneumoconiosis.

There have been only a few reports of pulmonary fibrosis and pneumoconiosis due to organic dust.. ${ }^{5}$ Sano investigated the pathogenesis of organic dust pneumoconiosis, showing that rats developed mild fibrosis and granulomas in the lungs after endotracheal infusion of saline containing organic dust, but this report has only been published in Japanese. ${ }^{5}$ In addition, one post-mortem study has suggested that cotton fibres cause pulmonary fibrosis in humans. ${ }^{7}$ The fibrosis observed in our patient was characterised by a peribronchiolar distribution and occupied the central area of the secondary lobules, developing around the string-like foreign bodies which we identified as inhaled cotton fibres. There was no evidence of honeycombing. These findings were similar to the histological distribution of interstitial lung disease associated with nylon flock. ${ }^{8}$ We therefore conclude that the fibrosis in our patient was causally related to the inhalation of cotton

This is the first histological evidence that cotton fibre inhalation may be related to a granulomatous reaction and peribronchial fibrosis in the lungs. Our findings support the possibility that, like inorganic dust, organic dust can also cause pneumoconiosis. The pulmonary opacities seen in our patient were predominantly localised at the lung bases, so it was difficult to distinguish this condition from idiopathic pulmonary fibrosis on plain chest radiographic films. A diagnosis of cotton dust pneumoconiosis may be suggested by occupational exposure, a bronchiolocentric distribution of lung changes on the HRCT scan, and detection of string-like
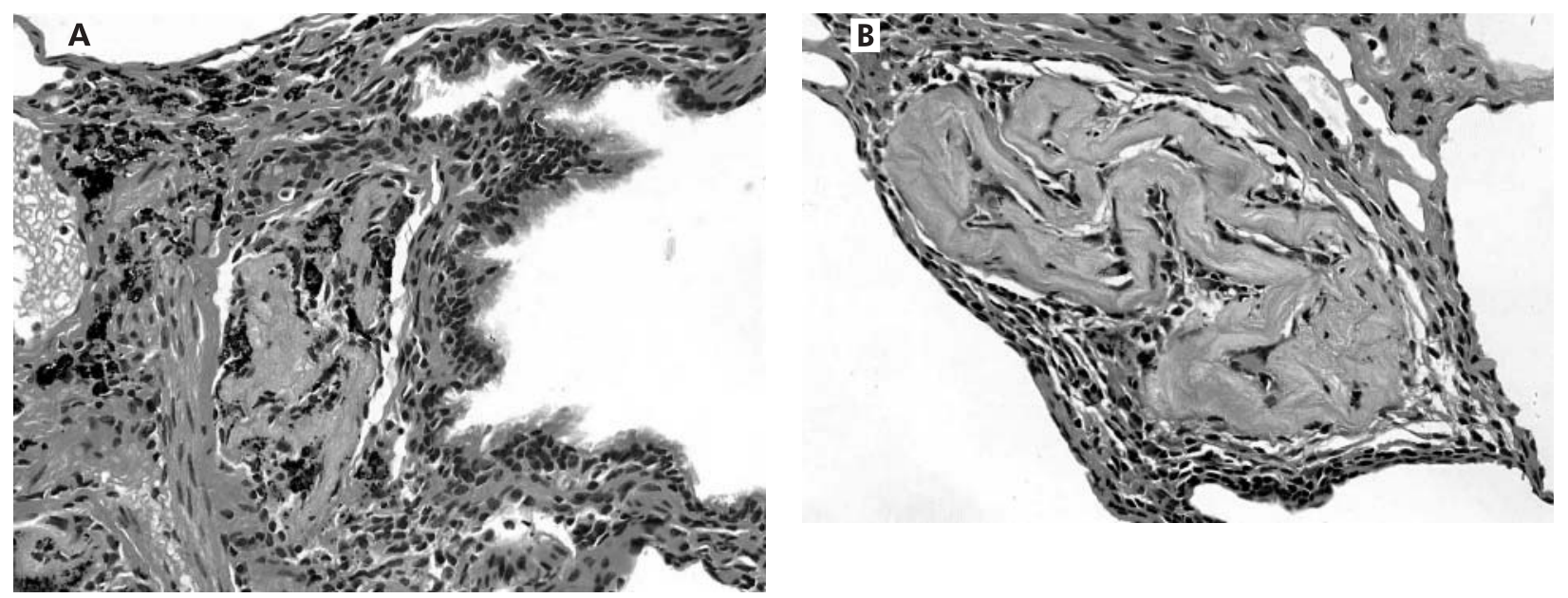

Figure 3 (A) High power view of the same specimen as in fig 2 showing an eosinophilic string-like foreign body in the bronchiolar wall. (B) A foreign body in the other portion. H\&E staining, magnification $\times 40$. Spectral analysis by infrared spectrophotometry showed that the foreign bodies had an identical pattern to that of cellulose. 
foreign bodies in lung biopsy specimens. The huge number of workers in industries handling cotton around the world should therefore be more careful about exposure to inhalation of cotton fibres.

\section{Authors' affiliations}

H Kobayashi, S Kanoh, K Motoyoshi, Third Department of Internal Medicine, National Defense Medical College, Saitama, Japan

S Aida, Department of Surgical Pathology, National Defense Medical College, Saitama, Japan

Correspondence to: Dr H Kobayashi, Third Department of Internal Medicine, National Defense Medical College, 3-2 Namiki, Tokorozawa City, Saitama 359-8513, Japan; kobahide@me.ndmc.ac.jp

Received 25 August 2003

Accepted 10 December 2003

\section{REFERENCES}

1 Niven R, Pickering CAC. Byssinosis and related diseases. In: Mapp CE, ed. Occupational lung disorders. European respiratory monograph 11. Sheffield: European Respiratory Society, 1999:286-300.

2 Merchant JA. Byssinosis. Occupational Respiratory Diseases. DHHS (NIOSH), September 1986: 86-102, http://www.cdc.gov/niosh/86-102.html (accessed 21 May 2003).

3 Rooke GB. The pathology of byssinosis. International conference on byssinosis. Chest 1981;79(Suppl):67-71s.

4 Edwards C, McCartney J, Rooke G, et al. The pathology of the lung in byssinotics. Thorax 1975;30:612-23.

5 Sano T. Pathology and pathogenesis of organic dust pneumoconiosis (Japanese). J Sci Labour 1967;43:3-18.

6 Abe A, Ishikawa T. Studies on pneumoconiosis caused by organic dusts (Japanese). J Sci Labour 1967;43:19-41.

7 Ruttner JR, Spycher MA, Engeler ML. Pulmonary fibrosis induced by cotton fiber inhalation. Path Microbiol (Basel) 1968;32:1-14.

8 Eschenbacher WL, Kreiss K, Lougheed MD, et al. Nylon flockassociated interstitial lung disease. Am J Respir Crit Care Med $1999 ; 159: 2003-8$

\section{Clinical Evidence - Call for contributors}

Clinical Evidence is a regularly updated evidence-based journal available worldwide both as a paper version and on the internet. Clinical Evidence needs to recruit a number of new contributors. Contributors are healthcare professionals or epidemiologists with experience in evidence-based medicine and the ability to write in a concise and structured way.

Areas for which we are currently seeking authors:

- Child health: nocturnal enuresis

- Eye disorders: bacterial conjunctivitis

- Male health: prostate cancer (metastatic)

- Women's health: pre-menstrual syndrome; pyelonephritis in non-pregnant women

However, we are always looking for others, so do not let this list discourage you.

Being a contributor involves:

- Selecting from a validated, screened search (performed by in-house Information Specialists) epidemiologically sound studies for inclusion.

- Documenting your decisions about which studies to include on an inclusion and exclusion form, which we keep on file.

- Writing the text to a highly structured template (about 1500-3000 words), using evidence from the final studies chosen, within 8-10 weeks of receiving the literature search.

- Working with Clinical Evidence editors to ensure that the final text meets epidemiological and style standards.

- Updating the text every six months using any new, sound evidence that becomes available. The Clinical Evidence in-house team will conduct the searches for contributors; your task is simply to filter out high quality studies and incorporate them in the existing text.

- To expand the topic to include a new question about once every 12-18 months.

If you would like to become a contributor for Clinical Evidence or require more information about what this involves please send your contact details and a copy of your CV, clearly stating the clinical area you are interested in, to Klara Brunnhuber (kbrunnhuber@ bmigroup.com).

\section{Call for peer reviewers}

Clinical Evidence also needs to recruit a number of new peer reviewers specifically with an interest in the clinical areas stated above, and also others related to general practice. Peer reviewers are healthcare professionals or epidemiologists with experience in evidence-based medicine. As a peer reviewer you would be asked for your views on the clinical relevance, validity, and accessibility of specific topics within the journal, and their usefulness to the intended audience (international generalists and healthcare professionals, possibly with limited statistical knowledge). Topics are usually 1500-3000 words in length and we would ask you to review between 2-5 topics per year. The peer review process takes place throughout the year, and our turnaround time for each review is ideally 10-14 days.

If you are interested in becoming a peer reviewer for Clinical Evidence, please complete the peer review questionnaire at www.clinicalevidence.com or contact Klara Brunnhuber (kbrunnhuber@bmigroup.com). 